Special issue of the 3rd International Conference on Computational and Experimental Science and Engineering (ICCESEN 2016)

\title{
Poly(2-acrylamido-2-methyl-1-propane sulfonic acid-co-1-vinyl-2-pyrrolidone) Hydrogel and its use in the Removal of $\mathrm{Cd}(\mathrm{II}), \mathrm{Pb}(\mathrm{II})$ and $\mathrm{Cu}(\mathrm{II})$
}

\author{
S. ÇAVUŞ* AND E. ÇAKAL
}

Istanbul University, Faculty of Engineering, Department of Chemical Engineering, Istanbul, Turkey

\begin{abstract}
Poly(2-acrylamido-2-methyl-1-propanesulfonic acid-co-1-vinyl-2-pyrrolidone), P(AMPS-co-VP), hydrogel was prepared by free radical cross-linking polymerization method. Prepared hydrogel was used in the competitive removal of $\mathrm{Cd}(\mathrm{II}), \mathrm{Pb}(\mathrm{II})$ and $\mathrm{Cu}(\mathrm{II})$ ions from aqueous solution. The characterization of $\mathrm{P}$ (AMPS-co-VP) before and after sorption was carried out by the Fourier transform infrared spectroscopy, thermogravimetric analysis and scanning electron microscopy. Atomic absorption spectrometer was used to found the concentration of metal ions in the aqueous solution. The selectivity of $\mathrm{P}(\mathrm{AMPS}-\mathrm{co}-\mathrm{VP})$ was as follows: $\mathrm{Cd}(\mathrm{II})>\mathrm{Pb}(\mathrm{II})>\mathrm{Cu}(\mathrm{II})$. Kinetic study showed that competitive removal of heavy metal ions on poly(AMPS-co-VP) was in accordance with a pseudosecond-order model.
\end{abstract}

DOI: 10.12693/APhysPolA.132.505

PACS/topics: sorption, heavy metal ions, hydrogels, sulfonic acid

\section{Introduction}

Heavy metals like $\mathrm{Cu}(\mathrm{II}), \mathrm{Ni}(\mathrm{II})$, and $\mathrm{Cd}(\mathrm{II})$ lead to many environmental problems and these toxic metals affect the human health seriously at even their low concentrations $[1,2]$. The removal of heavy metals has become a major problem since they do not have a biodegradable property naturally in the environment [1]. Hydrogels, hydrophilic, cross-linked and three-dimensional networks, have an excellent water absorbing capacity without being soluble [3-5]. These smart materials are widely used in the removal of heavy metal ions because of the presence of the functional groups (i.e. $-\mathrm{COOH},-\mathrm{SO}_{3} \mathrm{H},-\mathrm{OH}$, $-\mathrm{CONH}_{2}$ ) [4]. Polymers containing electron donor atoms like $\mathrm{N}, \mathrm{S}, \mathrm{O}$, and $\mathrm{P}$ can be named as polychelatogens and these atoms are used to form coordinate bonds with the heavy metals $[6,7]$.

In this study, 2-acrylamido-2-methyl-1-propane sulfonic acid (AMPS) and 1-vinyl-2-pyrrolidone (VP) were preferred to prepare hydrogels. AMPS is one of the important monomer with respect to its hydrolytically stable nature and strong acid functionality [7]. (VP) is a biocompatible monomer with high polymer surface activity [8]. Competitive removal of $\mathrm{Cd}(\mathrm{II}), \mathrm{Pb}(\mathrm{II})$, and $\mathrm{Cu}(\mathrm{II})$ was investigated at room temperature using $\mathrm{P}$ (AMPSco-VP) and the kinetic mechanism for the sorption of these ions on P(AMPS-co-VP) was determined. Detailed characterization study both before and after sorption was performed by the Fourier transform infrared spectroscopy (FTIR), thermogravimetric analysis (TGA) and scanning electron microscopy (SEM) techniques.

\footnotetext{
*corresponding author; e-mail: selva@istanbul.edu.tr
}

\section{Materials and methods}

\subsection{Materials}

AMPS and VP were of Merck Schuchardt OHG (Germany) product. $N, N^{\prime}$-methylenebisacrylamide (NMBA) and $N, N, N^{\prime}, N^{\prime}$-tetramethylethylenediamine (TEMED) were also provided by Merck Schuchardt OHG (Germany). Ammonium peroxydisulfate (APS) (Merck KGaA Darmstadt (Germany)) was used as the free radical initiator. Copper(II) acetate monohydrate, lead(II) acetate trihydrate and cadmium(II) acetate dihydrate were provided by Merck KGaA (Germany). Deionized water was used in the preparation of hydrogel and heavy metal ion solution.

\subsection{Preparation of hydrogel}

$\mathrm{P}$ (AMPS-co-VP) hydrogel was prepared by free-radical cross-linking polymerization in deionized water at $60^{\circ} \mathrm{C}$ for $24 \mathrm{~h}$. While APS was the initiator, NMBA and TEMED were used as cross-linking agent and accelerator, respectively. In the feed, the initial monomer concentration was kept constant at $1 \mathrm{~mol} / \mathrm{l}$ and the molar ratio of AMPS to VP was $80 / 20$. APS and NMBA were used as 1 and $5 \mathrm{~mol} . \%$ of the total monomer concentration, respectively, and the weight ratio of APS/TEMED was 1:1. Nitrogen gas bubbling (15 min) was applied to the solution containing cross-linker before the polymerization. $\mathrm{P}$ (AMPS-co-VP) in a cylindrical form was obtained in glass tubes (the inner diameter of $1.3 \mathrm{~cm}$ and length of $15 \mathrm{~cm}$ ). The gel was sliced into small cylindrical parts, and then was placed in deionized water by changing the water twice a day to remove the residual monomers and linear polymers. These gels were dried first in ambient temperature and then in vacuum oven at $40^{\circ} \mathrm{C}$. After grinding process, they were used in the sorption of metal ions. 
In order to determine the equilibrium swelling value (ESV) of $\mathrm{P}$ (AMPS-co-VP), a certain amount of the dry sample was placed in deionized water $\left(25^{\circ} \mathrm{C}\right)$ up to swelling equilibrium. ESV of the polymers was found from the following equation:

$\operatorname{ESV}\left(g_{\text {water }} / g_{\text {polymer }}\right)=\left(W_{s}-W_{d}\right) / W_{d}$.

$W_{s}$ is the weight of the swollen hydrogel and $W_{d}$ is the weight of the dry hydrogel.

\subsection{Characterization techniques}

FTIR analysis (Bruker Vertex 70 FT-IR Spectrometer) was performed to observe the changes in the structure of $\mathrm{P}$ (AMPS-co-VP) after the metal sorption. Thermal characterization of $\mathrm{P}$ (AMPS-co-VP) both before and after the metal sorption was performed by Shimadzu, DTG 60 instrument. Thermogravimetric analysis of samples was performed under nitrogen atmosphere (flow rate: $20 \mathrm{ml} / \mathrm{min})$ by heating from 25 to $800^{\circ} \mathrm{C}$ at a rate of $20^{\circ} \mathrm{C} / \mathrm{min}$. The SEM images of the P(AMPS-co-VP) and its metal sorbed counterpart were obtained using a JSM 5600, JEOL instrument.

\subsection{The removal of $C d(I I), P b(I I)$ and $C u(I I)$ and kinetics}

Batch sorption technique was used for the competitive removal of metal ions from aqueous solutions. The metal ion solution contains $\mathrm{Cd}(\mathrm{II}), \mathrm{Pb}(\mathrm{II})$, and $\mathrm{Cu}(\mathrm{II})$ ions together (the concentration of each metal is $200 \mathrm{mg} / \mathrm{l}$ ). A predetermined amount of polymer was added to the metal ion solution $(200 \mathrm{ml})$, and during the sorption experiments, the mixture was stirred at $25^{\circ} \mathrm{C}$ with a $200 \mathrm{rpm}$ rate. Atomic absorption spectrometer (AAS) (Varian Spectra AA 220-FS) was used to determine the concentration of metal ions. The following equations were used to calculate the experimental metal ion sorption capacities of the polymers [9-11]:

$$
\begin{aligned}
& q_{e}=\left(C_{0}-C_{e}\right) \frac{V}{m}, \\
& q_{t}=\left(C_{0}-C_{t}\right) \frac{V}{m} .
\end{aligned}
$$

Here, $q_{e}, q_{t}, C_{0}, C_{t}, C_{e}, V$ and $m$ show the amount of metal ion sorbed at equilibrium $[\mathrm{mg} / \mathrm{g}]$, the amount of metal ion sorbed at time $t[\mathrm{mg} / \mathrm{g}]$, the initial metal ion concentration $[\mathrm{mg} / \mathrm{L}]$, the concentration of metal solution at any time $[\mathrm{mg} / \mathrm{L}]$, concentration of metal ion in solution at equilibrium $[\mathrm{mg} / \mathrm{L}]$, the volume of metal ion in solution $[\mathrm{L}]$ and the amount of the polymer [g], respectively.

The change in $\mathrm{pH}$ of the metal ion solution with time was measured by a pH-meter (Orion $720 \mathrm{~A}+$, Thermo Electron Corporation, USA).

The sorption kinetics of $\mathrm{Cd}(\mathrm{II}), \mathrm{Pb}(\mathrm{II})$, and $\mathrm{Cu}(\mathrm{II})$ on poly(AMPS-co-VP) was investigated. The Lagergren pseudo first-order and pseudo-second-order models were applied to determine the sorption mechanism [9, 11-15].

Pseudo-first-order model

$\ln \left(q_{e}-q_{t}\right)=\ln q_{e}-k_{1} t$.

$$
t / q_{t}=1 /\left(k_{2} q e^{2}\right)+\left(1 / q_{e}\right) t .
$$

Here, $q_{e}[\mathrm{mg} / \mathrm{g}]$ and $q_{t}[\mathrm{mg} / \mathrm{g}]$ are the sorption capacity at equilibrium and at time $t$ [min], respectively. The kinetic rate constants for the pseudo-first-order and the pseudosecond-order models are $k_{1}[1 / \mathrm{min}]$ and $k_{2}[\mathrm{~g} /(\mathrm{mg} \mathrm{min})]$, respectively.

The initial sorption rate constant, $h[\mathrm{mg} /(\mathrm{g}$ min $)]$, was found using $k_{2}$ and $q_{e}[9,13,14]$ :

$$
h=k_{2} q_{e}^{2} \text {. }
$$

\section{Results and discussion \\ 3.1. FTIR analysis of the gels}

FTIR technique was used for the structural characterization of polymers and the spectra have been given in Fig. 1. The band between 3000 and $3600 \mathrm{~cm}^{-1}$ is due to the stretching of $\mathrm{N}-\mathrm{H}$ and $\mathrm{O}-\mathrm{H}[7,9]$. In the spectrum of $\mathrm{P}(\mathrm{AMPS}-\mathrm{co}-\mathrm{VP})$, stretching vibration of $\mathrm{C}=\mathrm{O}$ (amide I band) results from the amide group is seen at $1643 \mathrm{~cm}^{-1}[4,7,9]$. Both the intensity and band position of amide I band decrease in the spectrum of metal sorbed gel. The bands seen at $1540 \mathrm{~cm}^{-1}$ are attributed to the amide II band $[4,9]$. The intensity of amide II band increased after sorption because of the coordination of metal ions [7]. The shifting of this band is also evident because of the sorption of metal ions. The stretching of $\mathrm{C}-\mathrm{N}$ bond is seen at $1456 \mathrm{~cm}^{-1}[4,7]$. The band at $1036 \mathrm{~cm}^{-1}$ in the spectrum of $\mathrm{P}$ (AMPS-co-VP) is assigned to the symmetric stretching of $\mathrm{S}=\mathrm{O}$ group $[4,7,9]$ and it shifts to the lower wave number $\left(1027 \mathrm{~cm}^{-1}\right)$ in the spectrum of metal sorbed gel.

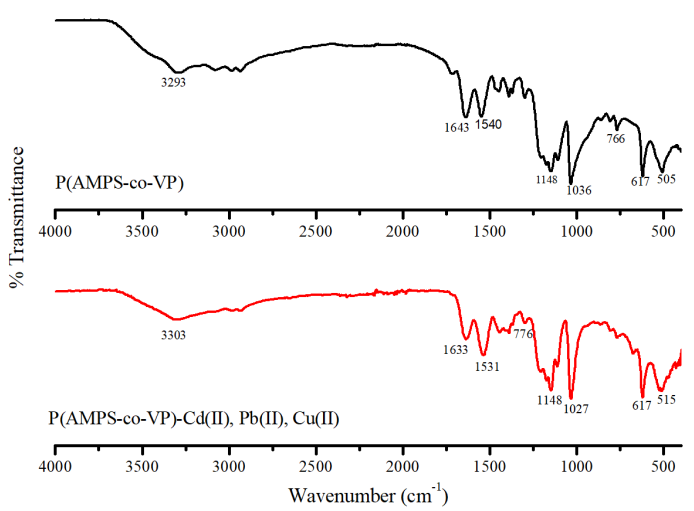

Fig. 1. FTIR spectra of P(AMPS-co-VP) before and after removal experiments.

The changes in the wave numbers and intensities of the bands after the sorption process are attributed to metal sorption through ion exchange between the metal ions and $-\mathrm{SO}_{3} \mathrm{H}$ groups.

\subsection{Thermal characterization}

The thermal properties of P(AMPS-co-VP) both before and after sorption were studied by TGA, and corresponding thermograms are shown in Fig. 2. Sorption process strongly affected the thermal stability and degradation steps of polymers. Metal sorbed form of polymer displayed higher thermal stability than pristine P(AMPSco-VP). 


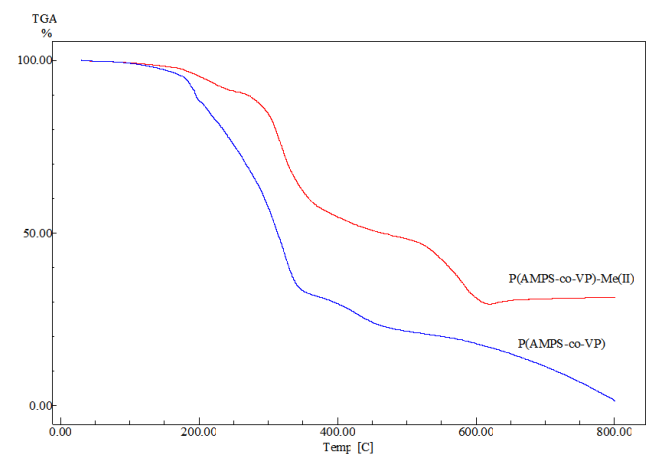

Fig. 2. Thermograms of $\mathrm{P}(\mathrm{AMPS}-\mathrm{co}-\mathrm{VP})$ before and after removal experiments.

While the degradation between 250 and $300{ }^{\circ} \mathrm{C}$ is due to the $-\mathrm{SO}_{3} \mathrm{H}$ groups decomposition $[9,16]$, the main chain degradation and following cross-linking bridges can be seen at $300-500{ }^{\circ} \mathrm{C}[9,16]$. 44 and $15.8 \%$ mass loss was observed starting from 25 to $300^{\circ} \mathrm{C}$ for P(AMPS-co-VP) and its metal sorbed counterpart, respectively. At $500^{\circ} \mathrm{C}$ their mass losses became 81.2 and $52.8 \%$.

\subsection{Morphology}

The morphologic character of $\mathrm{P}$ (AMPS-co-VP) differ from the P(AMPS-co-VP)-Me(II) (Fig. 3). P(AMPS-co$\mathrm{VP})$ has irregular, rough and cracked structure before sorption but less rough nature was seen after sorption.
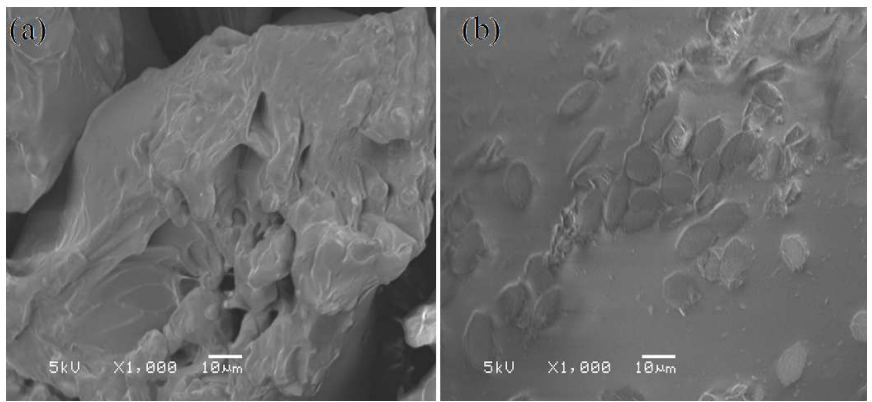

Fig. 3. SEM images of $\mathrm{P}(\mathrm{AMPS}-\mathrm{co}-\mathrm{VP})$ : (a) before and (b) after removal experiments.

\subsection{Sorption study and kinetics}

$\mathrm{P}$ (AMPS-co-VP) gel was used to investigate its efficiency on the competitive removal of $\mathrm{Cu}(\mathrm{II}), \mathrm{Pb}(\mathrm{II})$, and $\mathrm{Cd}$ (II) ions from aqueous solution at room temperature. During the removal of metal ions, the $\mathrm{pH}$ of solution was also measured. Kinetics of sorption of $\mathrm{Pb}(\mathrm{II}), \mathrm{Cu}(\mathrm{II})$, and $\mathrm{Cd}(\mathrm{II})$ ions on $\mathrm{P}$ (AMPS-co-VP) was investigated for pseudo-first and second-order kinetics. In addition, ESV of the hydrogel was determined and it was found to be $236 \mathrm{~g}_{\mathrm{H} 2 \mathrm{O}} / \mathrm{g}_{\text {polymer }}$. The $\mathrm{pH}$ of solution strongly affects the sorption process especially in terms of the complexation mechanism. In this case, the optimum $\mathrm{pH}$ for the removal of metal ions should be considered. The $\mathrm{pH}-$ dependent selectivity of the polymers was reported previously $[1,7,17]$.
In the study of Valle et al. [7], the linear $\quad \operatorname{poly}(N$-vinylpyrrolidone-co-2-acrylamido-2methylpropanesulfonate sodium), poly(VP-co-AMPS), was prepared and used for the removal of $\mathrm{Cu}(\mathrm{II})$, $\mathrm{Cd}(\mathrm{II})$, and $\mathrm{Ni}(\mathrm{II})$. The metal ion retention capacity of PAMPS did not change at pHs 3.2 and 5.7. There is no competition among the hydrogen ions and the metal ions due to pKa value (1.5) of sulfonic acid group [7]. They reported that linear poly(VP-co-AMPS) includes electrostatic and coordination interactions together for the metal ions due to AMPS and VP monomer units [7]. In our study, the initial $\mathrm{pH}$ value of the prepared metal ion solution was 6.21 and after 5 min it was measured as 5.03. At equilibrium, the measured $\mathrm{pH}$ value is 4.50 and the decrease in $\mathrm{pH}$ can be attributed to the exchange of metal ions with $\mathrm{H}^{+}$.

The sorption capacities of $\mathrm{P}(\mathrm{AMPS}-\mathrm{co}-\mathrm{VP})$ for $\mathrm{Cd}(\mathrm{II})$, $\mathrm{Pb}(\mathrm{II})$, and $\mathrm{Cu}(\mathrm{II})$ ions versus time are presented in Fig. 4. The lowest sorption capacity value was observed for $\mathrm{Cu}(\mathrm{II})$. The removal of metal ions (in equilibrium) occurs in the order of $\mathrm{Cd}(\mathrm{II})(70.26 \mathrm{mg} / \mathrm{g})>\mathrm{Pb}(\mathrm{II})$ $(63.23 \mathrm{mg} / \mathrm{g})>\mathrm{Cu}(\mathrm{II})(56.15 \mathrm{mg} / \mathrm{g})$. It can be concluded that the sorption capacity values of $\mathrm{P}$ (AMPS-co-VP) are satisfactory despite the high volume of the metal ion solution and high initial concentration of the metal ions.

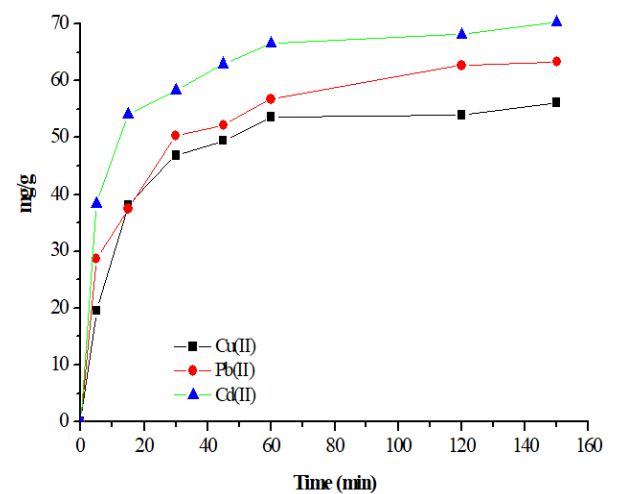

Fig. 4. The sorption capacity of P(AMPS-co-VP).

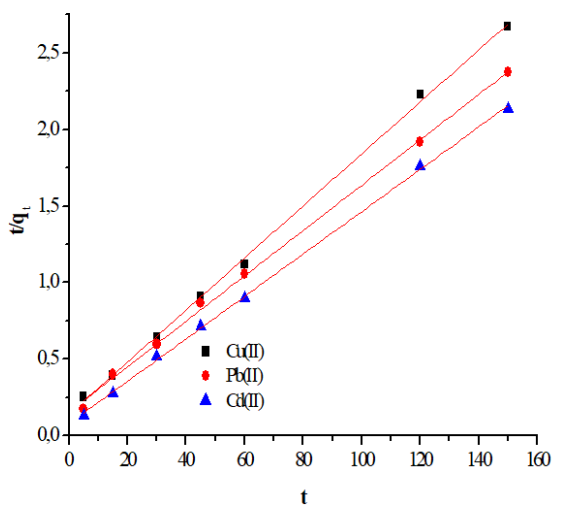

Fig. 5. Pseudo-second-order kinetic model plots.

The pseudo-second-order plot for the removal of $\mathrm{Cd}(\mathrm{II}), \mathrm{Pb}(\mathrm{II})$, and $\mathrm{Cu}(\mathrm{II})$ ions on $\mathrm{P}$ (AMPS-co-VP) was 
depicted in Fig. 5 and the kinetic parameters are given in Table I. The correlation coefficients $\left(R^{2}\right)$ are very high for the pseudo-second-order and $q_{\text {exp }}$ and $q_{\text {theo }}$ are very close. This shows that removal of $\mathrm{Cd}(\mathrm{II}), \mathrm{Pb}(\mathrm{II})$, and $\mathrm{Cu}(\mathrm{II})$ ions is explained well by a pseudo-second-order kinetic model. In the case of pseudo-second-order model, the rate-limiting step may occur by a chemical sorption [18]. The initial sorption rate $(h)$ is calculated using the second order rate constant $\left(k_{2}\right)$ and $q_{e}$. The order for $k_{2}$ and $h$ were $\mathrm{Cd}(\mathrm{II})>\mathrm{Cu}(\mathrm{II})>\mathrm{Pb}(\mathrm{II})$. The initial sorption rates for the removal of $\mathrm{Pb}(\mathrm{II})$ and $\mathrm{Cu}(\mathrm{II})$ on the $\mathrm{P}$ (AMPSco-VP) are very similar and they are considerably lower than that of $\mathrm{Cd}(\mathrm{II})$, which support the highest sorption capacity for the $\mathrm{Cd}(\mathrm{II})$.

TABLE I

The kinetic parameters.

\begin{tabular}{l|c|c|c}
\hline \hline \multicolumn{1}{c|}{ Parameters } & $\mathrm{Cd}(\mathrm{II})$ & $\mathrm{Pb}(\mathrm{II})$ & $\mathrm{Cu}(\mathrm{II})$ \\
\hline$q_{\exp }[\mathrm{mg} / \mathrm{g}]$ & 70.26 & 63.23 & 56.15 \\
$q_{\text {theo }}[\mathrm{mg} / \mathrm{g}]$ & 72.46 & 67.57 & 58.80 \\
$k_{2} \times 10^{3}[\mathrm{~g} /(\mathrm{mg}$ min) $]$ & 2.411 & 1.416 & 2.024 \\
$R^{2}$ (pseudo-second-order) & 0.9994 & 0.9985 & 0.9990 \\
$R^{2}$ (pseudo-first-order) & 0.8870 & 0.9985 & 0.7875 \\
$h[(\mathrm{mg} /$ (g min) $]$ & 12.66 & 6.46 & 7.00
\end{tabular}

\section{Conclusion}

The removal capacity of $\mathrm{P}(\mathrm{AMPS}-\mathrm{co}-\mathrm{VP})$ hydrogel for $\mathrm{Cd}(\mathrm{II})$ is higher than that of $\mathrm{Pb}(\mathrm{II})$ and $\mathrm{Cu}(\mathrm{II})$. The sorption of $\mathrm{Pb}(\mathrm{II}), \mathrm{Cu}(\mathrm{II})$, and $\mathrm{Cd}(\mathrm{II})$ ions on $\mathrm{P}$ (AMPS-co$\mathrm{VP})$ are well represented by the pseudo-second-order kinetic model. The change in the morphology and thermal stability of $\mathrm{P}$ (AMPS-co-VP) before and after sorption is evident.

\section{Acknowledgments}

This work was supported by Scientific Research Project Coordination Unit of Istanbul University. Project number: 2687.

\section{References}

[1] A. Petrovič, M. Simonič, Int. J. Environm. Sci. Technol. 13, 1761 (2016).

[2] M. El Tokhi, B.M. Amin, S. Alaabed, Acta Phys. Pol. A 130, 138 (2016).

[3] U. Yildiz, Ö.F. Kemik, B. Hazer, J. Hazard. Mater. 183, 521 (2010).

[4] I. Clara, R. Lavanya, N. Natchimuthu, J. Macromol. Sci. A Pure Appl. Chem. 53, 492 (2016).

[5] F. Akti, F. Boran, Acta Phys. Pol. A 130, 147 (2016).

[6] A.M. Atta, H.S. Ismail, A.M. Elsaaed, J. Appl. Polym. Sci. 123, 2500 (2012).

[7] H. Valle, J. Sanchez, B.L. Rivas, J. Appl. Polym. Sci. 132, 41272 (2015)

[8] J. Guo, L. Li, Y. Ti, J. Zhu, Express Polym. Lett. 1, 166 (2007).

[9] S. Çavuş, G. Yaşar, Y. Kaya, Z.B. Gönder, G. Gürdağ, I. Vergili, Process Safety Environm. Protect. 103, 227 (2016).

[10] P.V. Dadhaniya, M.P. Patel, R.G. Patel, J. Macromol. Sci. A Pure Appl. Chem. 44, 769 (2007).

[11] H. Chen, A. Wang, J. Hazard. Mater. 165, 223 (2009).

[12] Y.S. Ho, G. McKay, Process Biochem. 34, 451 (1999).

[13] M.H. Kalavathy, T. Karthikeyan, S. Rajgopal, L.R. Miranda, J. Coll. Interf. Sci. 292, 354 (2005).

[14] Y.-S. Ho, J. Hazard. Mater. B 136, 681 (2006).

[15] B. Tugrul, S. Erentürk, S. Haciyakupoglu, N. Karatepe, N. Altinsoy, N. Baydogan, F. Baytas, B. Büyük, E. Demir, S. Gedik, Acta Phys. Pol. A 128, B-180 (2015)

[16] J. Qiao, T. Hamaya, T. Okada, Polymer 46, 10809 (2005).

[17] F. Ge, M-M. Li, H. Ye, B.-X. Zhao, J. Hazard. Mater. 211-212, 366 (2012)

[18] Y.S. Ho, G. McKay, Water Res. 34, 735 (2000). 